\title{
Painful procedures and pain management in newborns admitted to an intensive care unit*
}

\author{
Procedimentos dolorosos e manejo da dor em recém-nascidos hospitalizados em unidade \\ de terapia intensiva \\ Procedimientos dolorosos y manejo del dolor en recién nacidos hospitalizados en Unidad \\ de Cuidados Intensivos
}

How to cite this article:

Rocha VA, Silva IA, da Silveira Cruz-Machado S, Bueno M. Painful procedures and pain management in newborns admitted to an intensive care unit. Rev Esc Enferm USP. 2021;55:e20210232. https://doi.org/10.1590/1980-220X-REEUSP-2021-0232

\section{Vanderlei Amadeu da Rocha ${ }^{1}$ \\ Isília Aparecida Silva ${ }^{2}$ \\ Sanseray da Silveira Cruz-Machado ${ }^{3}$ \\ iD Mariana Bueno ${ }^{4}$}

* Extracted from the thesis: "Dor em recém-nascidos hospitalizados em unidade de terapia intensiva: aspectos fisiológicos, comportamentais e endócrinos", Universidade de São Paulo, Escola de Enfermagem, 2020.

${ }^{1}$ Universidade de São Paulo, Hospital Universitário, Unidade de Terapia Intensiva Pediátrica e Neonatal, São Paulo, SP, Brazil.

${ }^{2}$ Universidade de São Paulo, Escola de Enfermagem, Departamento de Enfermagem Materno-Infantil e Psiquiátrica, São Paulo, SP, Brazil.

${ }^{3}$ Universidade Federal de São Paulo, Escola Paulista de Medicina, Departamento de Farmacologia, São Paulo, SP, Brazil.

${ }^{4}$ The Hospital for SickChildren, Canadá.

\section{ABSTRACT}

Objective: To characterize painful procedures, analgesic strategies, vital signs, and pain scores in hospitalized newborns. Method: This is a primary, observational, prospective clinical study, developed in a Brazilian public hospital. Demographic data, painful procedures, pain relief measures, vital signs, and pain scores were collected from the clinical records of 90 newborns admitted to the intensive care unit and evaluated between admission and the third day of admission. For statistical analysis, the software Statistic Package for the Social Sciences and the R Software were used. Results: Newborns underwent 2,732 painful procedures, 540 non-pharmacological and 216 pharmacological strategies. The most frequently performed procedure was the heel prick $(20.96 \%)$. The most commonly recorded non-pharmacological strategy was dim lighting $(28.33 \%)$ and continuous fentanyl (48.83\%) was the main pharmacological measure adopted. Pain score and vital signs show variability in the period evaluated. Conclusion: Despite the high number of painful procedures, pain assessment records do not reflect procedural pain and the use of analgesic strategies was insufficient.

\section{DESCRIPTORS}

Pain; Infant, Newborn; Critical Care. 


\section{INTRODUCTION}

The Neonatal Intensive Care Unit (NICU) is, in general, a stress-causing environment, in which several factors can contribute to the newborn (NB) homeostasis disturbance ${ }^{(1)}$. Among these factors, the high amount of manipulations is highlighted, often being painful and stressful, due to clinical instability and the need to carry out invasive therapeutic and diagnostic procedures, such as tracheal intubation, blood collection, insertion of venous catheters, among other procedures ${ }^{(2)}$. Studies conducted in low, middle, and high income countries show that the average number of painful procedures performed during hospitalization in the NICU varies between 7.5 and 17.3 procedures per day ${ }^{(3)}$.

Pain is defined as an unpleasant sensory and emotional experience, associated or similar to that of actual or potential tissue damage ${ }^{(4)}$. Pain activates compensatory mechanisms of the autonomic nervous system and produces a range of behavioral, physiological, and hormonal responses, which can be used as clinical pain assessment tools ${ }^{(5)}$.

Over the last decades, there has been a significant advance in relation to the understanding of pain in $\mathrm{NBs}$ and the production of knowledge related to the assessment and management of neonatal pain. However, it is pointed out that, despite the large number of clinical pain assessment instruments, these are not routinely used and the assessment remains controversial ${ }^{(6)}$. Additionally, it appears that the implementation of analgesic measures is inadequate and insufficient in neonatal units ${ }^{(3,6,7)}$. In addition, studies demonstrate insufficient knowledge of health professionals about several aspects related to neonatal pain in the Brazilian context ${ }^{(6,8)}$.

These findings emphasize an important gap between scientific knowledge and clinical practice in relation to the management of neonatal pain. Due to the high number of painful situations to which they are exposed, pain management in hospitalized NBs is essential. Thus, the identification of painful procedures performed in NBs admitted to the NICU, as well as pain assessment and control practices, will contribute to a better understanding of neonatal pain management.

The present study aimed to characterize the number and type of painful procedures performed, the values of heart rate, respiratory rate, blood pressure and peripheral oxygen saturation, as well as the records of pain scores, pharmacological and non-pharmacological measures of pain relief, from admission (D0) to the third day of hospitalization (D3) in NBs admitted to the NICU.

\section{METHOD}

\section{Design of Study}

This is a primary, observational and prospective clinical study.

\section{Design and Local of Study}

The population consisted of $90 \mathrm{NBs}$ who needed support from the NICU. The study was carried out in a public university hospital located in the city of São Paulo, Brazil. This is a mixed ICU unit, designed to care for pediatric and neonatal patients. The NICU and Pediatric environments are physically distinct, and the former unit has six beds to care for critically ill NBs (birth to 28 days of life). The nursing team consists of 12 nurses and 26 nursing technicians. The number of professionals who provide care to newborns is proportional to the number of patients, varying according to the dynamics of the unit and throughout the day. On average, each professional provides care to two newborns per shift. The team also has physicians, physiotherapists, speech therapists, among other professionals.

\section{Selection Criteria}

Newborns from the Obstetric Center (OC) and admitted to the NICU were considered eligible. Newborns diagnosed with grade III or IV intraventricular hemorrhage, hydrocephalus, microcephaly, and genetic syndromes were excluded from this study.

\section{Sample Definition}

To calculate the sample size, the software nQuery Advisor (version 7.0) was used. The number of 84 subjects was stipulated for a significance level of 5\% (Type I error) and a correlation equal to or greater than 0.3 with a $20 \%$ type II error. Due to possible losses, $5 \%$ was added to the initially calculated sample, totaling $90 \mathrm{NBs}$.

\section{Data Collection}

Data were collected between March 2018 and June 2019. The nursing staff working in the field unit of the study received prior training at the beginning of collection. The topics covered included aspects related to pain in the $\mathrm{NB}$, information related to the research, as well as guidelines for filling out the printed document, regarding the number and type of painful procedures performed and pharmacological and non-pharmacological measures used.

The NB's characterization data were obtained from the medical records: type of delivery, sex, gestational age at birth (in complete weeks), Apgar score, birth weight, and initial clinical diagnosis(s). The number and type of procedures performed (including unsuccessful attempts), as well as non-pharmacological analgesia and/or comfort strategies and pharmacological analgesia and sedation strategies, were recorded by the nursing professional, responsible for the care of the NB, in a form developed for the present study, based on an instrument used in previous research ${ }^{(7)}$ and adapted to the unit of the field of study. The following procedures were considered painful: venipuncture (IV therapy), venipuncture (blood collection), heel prick, capillary puncture (blood spot screening test), arterial puncture (blood collection), intramuscular puncture, tracheal intubation, tracheal extubation, mechanical ventilation, CPAP (Continuous Positive Airway Pressure) insertion, nasal catheter insertion, upper airway (UAW) aspiration and/or cannula, gastric probing, insertion of a Peripherally Inserted Central Catheter (PICC), passage of umbilical catheter, central 
catheter insertion, urinary catheter, CSF collection, respiratory physiotherapy, dressing, removal of devices, and other procedures (surgery, for example).

Data regarding heart rate, respiratory rate, blood pressure, peripheral oxygen saturation and pain scores, measured by the Neonatal Infant Pain Scale (NIPS) ${ }^{(9)}$ were obtained from clinical records. These data are routinely checked by the nursing staff and recorded at 4-hour intervals (8am; 12; 4pm; 8pm; 0h; 4am). Data were collected from admission (D0) to the third day (D3) of the NB's admission to the NICU.

\section{Data Analysis and Treatment}

Data were stored in spreadsheets in Microsoft Excel for Windows (Enterprise/2007). The analysis was performed using the software Statistic Package for the Social Sciences (SPSS Inc., Chicago, IL, USA) and the R Software (version 2.15.2). For the descriptive analysis, absolute and relative frequency values for categorical variables were presented. For numerical variables, measures of central tendency were used. To test the statistical differences of the data, one-way analysis of variance (one-way ANOVA) and Tukey's post-test were performed. For the correlations, the Spearman Correlation test (Graph PadPrism, version 6) was used. The established level of significance was 0.05 .

\section{Ethical AspeCts}

The study was approved by the Research Ethics Committees of the institutions involved, (Opinions 1.833.194/2016 and 1.870.943/2016) and conducted in accordance with resolution 466/2012. Those responsible for the NBs were approached upon admission to the NICU or at the Rooming-in Unit (place of hospitalization of mothers) and were invited to participate in the study. When they agreed, they signed the Free Informed Consent Form and, in the case of underage parents, the Assent Term.

\section{RESULTS}

During the period of data collection, 119 NBs were admitted to the study field unit. Of these, 29 were excluded because they came from the Pediatric Emergency Room $(n=19)$ and from the Intermediate Care Unit $(n=10)$.

Ninety NBs participated in the study. Most were born through cesarean section $(\mathrm{n}=48 ; 53.33 \%)$ (Figure $1 \mathrm{~A})$, were male ( $\mathrm{n}=56 ; 62.22 \%$ ) (Figure $1 \mathrm{~B})$, with an average birth weight of $2.56 \mathrm{~kg}( \pm 1$, minimum $0.51 \mathrm{~kg}$, maximum $4.47 \mathrm{~kg}$ ) (Figure 1C). Mean gestational age at birth was 35 weeks, $( \pm 5$, minimum 21 , maximum 44 weeks) (Figure 1D). Most were classified as adequate for gestational age (AGA) ( $\mathrm{n}=79 ; 87.78 \%$ ) (Figure 1E). In addition, 44 (48.88\%) were considered as preterm, $44(48.88 \%)$ as term, and only two $(2.22 \%)$ as post-term (Figure $1 \mathrm{~F})$. The average Apgar score in the $1^{\text {st }}$ minute was $6.03( \pm 2.67)$, in the $5^{\text {th }}$ minute of life was $7.51( \pm 1.95)$, and in the $10^{\text {th }}, 8.63( \pm 1.49)$ (Figure $\left.1 \mathrm{G}\right)$.

$\mathrm{Up}$ to three clinical diagnoses were collected by NB on admission, the most prevalent being: early respiratory distress $(n=54 ; 60 \%)$, low weight $(n=16 ; 17.78 \%)$, risk of meconium aspiration syndrome $(n=15 ; 16.67 \%)$, infection risk $(n=10 ; 11.11 \%)$, and premature labor $(n=9 ; 10 \%)$.

Between D0 and D3, the NBs included in the study underwent 2,732 painful procedures, with a mean of $30.36( \pm 20.47)$ procedures per NB during the study period (Table 1). A total of 540 non-pharmacological strategies for comfort and pain relief were recorded, mean of $5.98( \pm 5.11)$, and 216 pharmacological interventions, mean of 2.39 $( \pm 4.66)$, for pain relief during the period of study (Table 1 ).

There is a variation in the number of procedures from admission (D0) to the third day (D3) of admission. On D0, the mean of procedures performed was $12.78( \pm 6.02)$;
A

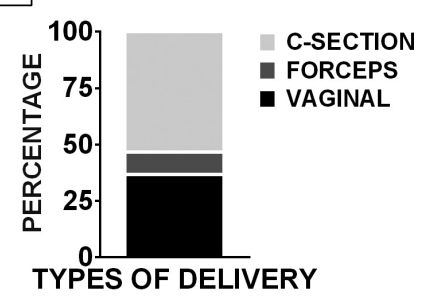

B

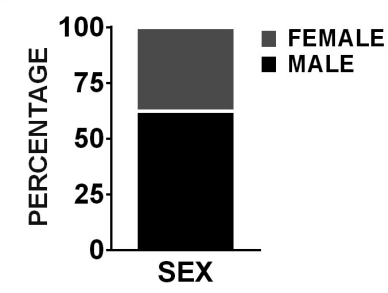

C

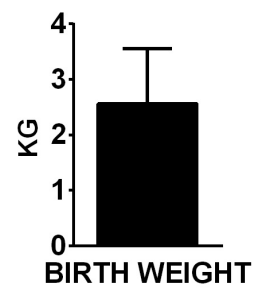

D

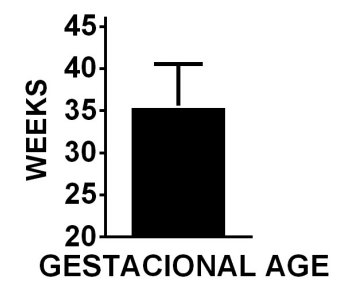

E

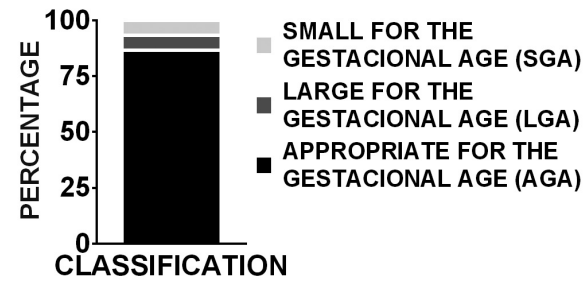

$\mathbf{F}$

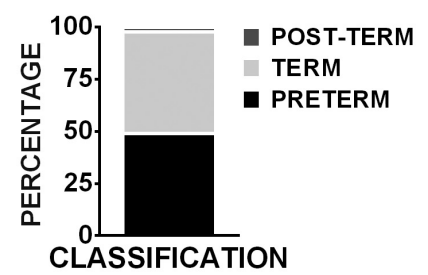

$\mathbf{G}$

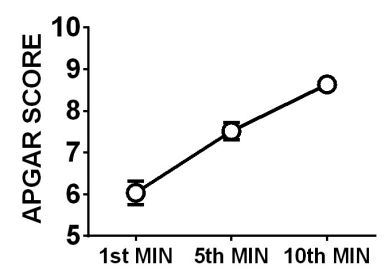

Figure 1 - Characterization of the NB included in the study regarding: (A) type of delivery; (B) sex; (C) birth weight (in kg); (D) gestational age at birth (in complete weeks); (E) classification in relation to weight and gestational age; (F) classification in relation to gestational age at birth, and $(\mathrm{G})$ Apgar score $\left(1^{\text {st }}, 5^{\text {th }}\right.$, and $10^{\text {th }}$ minutes of life). São Paulo, 2020. 
Table 1 - Total number of procedures, non-pharmacological and pharmacological measures per NB, performed from admission (D0) to the third day (D3) of admission to the NICU.SD: Standard Deviation - São Paulo, SP, Brazil, 2020.

\begin{tabular}{|c|c|c|c|c|c|c|}
\hline Variable & $\mathbf{N}$ & Mean & SD & Min & Median & Max \\
\hline Number of procedures & 2732 & 30.36 & 20.47 & 4 & 27.5 & 91 \\
\hline Non-pharmacological measures & 540 & 5.978 & 5.11 & 0 & 6 & 21 \\
\hline Pharmacological measures & 216 & 2.39 & 4.66 & 0 & 0 & 22 \\
\hline
\end{tabular}

A

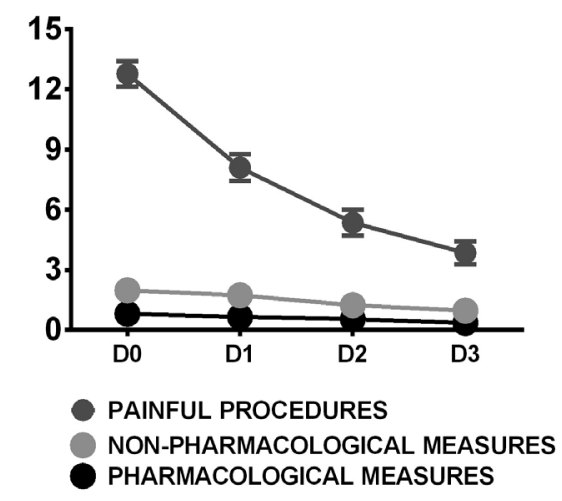

C

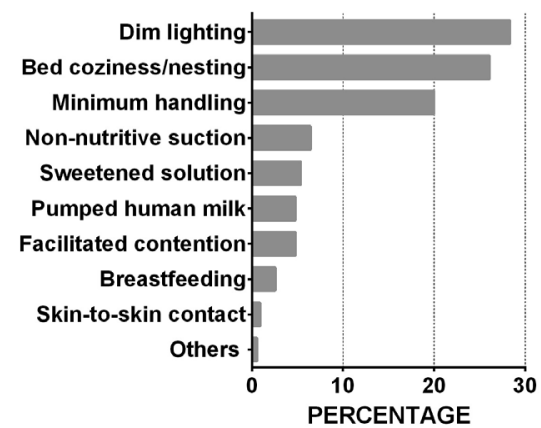

B

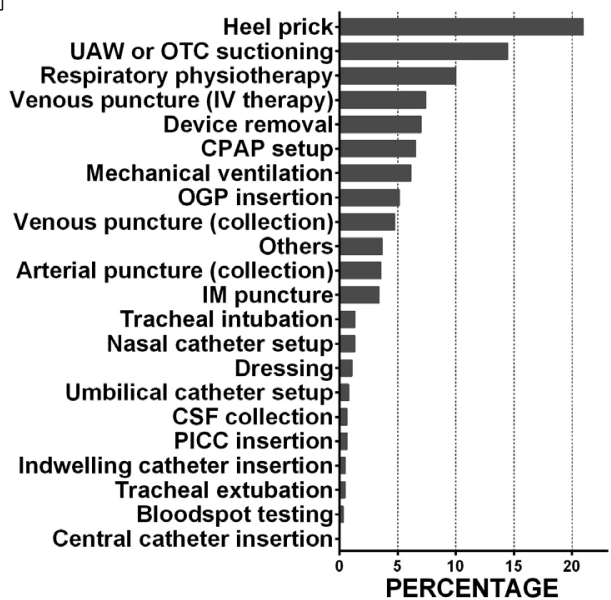

D

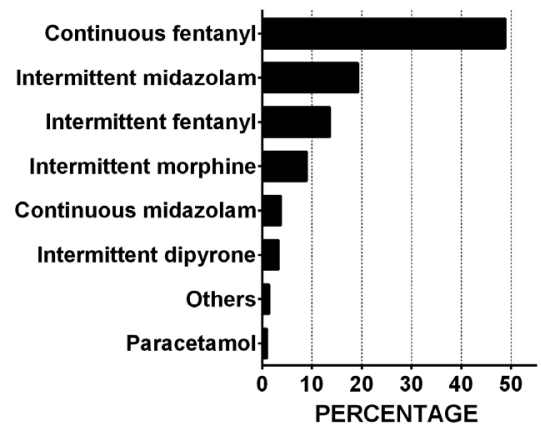

Figure 2 - (A) Mean number of potentially painful procedures, non-pharmacological and pharmacological strategies from admission (D0) to the third day (D3) of admission to the NICU; (B) Painful procedures; (C) Non-pharmacological strategies; (D) Pharmacological strategies. São Paulo, 2020.

at D1, 8.1 ( \pm 6.38$)$; in D2, the mean was $5.36( \pm 6.095)$, and in D3, $3.84( \pm 5.55)$ (Figure 2A). Regarding non-pharmacological strategies, the means were $1.98( \pm 2.39)$ interventions, 1.73 $( \pm 2.47), 1.23( \pm 2.42)$ and $0.97( \pm 2.11)$, respectively (Figure $2 \mathrm{~A})$. As for the pharmacological strategies, means of $0.81( \pm 2.04)$, $0.66( \pm 1.27), 0.544( \pm 1.23)$, and $0.36( \pm 0.96)$, respectively (Figure 2A), were recorded.

There was a statistically significant difference between the number of painful procedures performed over the days of hospitalization (one-way ANOVA), when comparing D0 and D1 ( $<<0.0001)$, D0 and D2 ( $<<0.0001)$, D0 and D3 ( $p<0.0001)$, D1 and D2 ( $<<0.05)$, D1 and D3 ( $<<0.0001)$. Moreover, there was a statistically significant difference regarding the non-pharmacological measures used between D0 and D3 ( $<<0.05)$. There was no significant difference regarding the use of pharmacological measures over the study period.
The most common painful procedure performed was the heel prick ( $\mathrm{n}=561 ; 20.96 \%$ ) (Figure $2 \mathrm{~B}$ ). As for nonpharmacological strategies, dim lighting $(n=153 ; 28.33 \%)$ was the most frequently recorded (Figure $2 \mathrm{C}$ ). Continuous fentanyl was the most commonly used drug $(n=104 ; 48.83 \%)$ (Figure 2D).

Heart rate, respiratory rate, blood pressure, and peripheral oxygen saturation values are shown in Table 2. Regarding pain assessment, 356 records of NIPS scores were found in D0, 402 records in D1, 286 records in D2, and 213 pain score records on D3. It is noted that the percentage of $\mathrm{NB}$ with pain (NIPS > 3) varies over the days and it is observed that, on D0, only $20(5.61 \%)$ of the recorded scores correspond to the presence of pain; on D1, only $10(2.49 \%)$ records; in D2, four (1.14\%); and on D3, three (1.14\%) records (Figure $3 \mathrm{~A}-\mathrm{D})$.

Finally, potential correlations between the number of procedures and other variables (gestational age, Apgar, birth 
Table 2 - Vital signs from admission (D0) to the third day (D3) of admission to the NICU - São Paulo, SP, Brazil, 2020.

\begin{tabular}{|c|c|c|c|c|c|c|c|}
\hline Variable & Day & $\mathbf{N}^{*}$ & Mean & SD & Min & Median & Max \\
\hline \multirow{4}{*}{ Heart rate } & Day 0 & 346 & 137.9 & 16.5 & 78 & 137.5 & 186 \\
\hline & Day 1 & 396 & 136.9 & 15.97 & 80 & 137 & 195 \\
\hline & Day 2 & 280 & 140.7 & 17.96 & 96 & 140 & 199 \\
\hline & Day 3 & 207 & 147.4 & 18.16 & 93 & 150 & 184 \\
\hline \multirow{4}{*}{ Respiratory rate } & Day 0 & 345 & 55.37 & 15.04 & 22 & 54 & 114 \\
\hline & Day 1 & 395 & 56.05 & 14.81 & 22 & 54 & 104 \\
\hline & Day 2 & 279 & 54.75 & 12.72 & 29 & 54 & 100 \\
\hline & Day 3 & 206 & 51.97 & 13.51 & 27 & 52 & 96 \\
\hline \multirow{4}{*}{ Peripheral oxygen saturation } & Day 0 & 341 & 96 & 5.11 & 46 & 97 & 100 \\
\hline & Day 1 & 391 & 96.55 & 2.40 & 85 & 97 & 100 \\
\hline & Day 2 & 277 & 96.13 & 2.74 & 83 & 97 & 100 \\
\hline & Day 3 & 196 & 96.06 & 3.14 & 69 & 97 & 100 \\
\hline \multirow{4}{*}{ Systolic pressure } & Day 0 & 341 & 58.76 & 11.72 & 23 & 58 & 114 \\
\hline & Day 1 & 387 & 58.44 & 10.83 & 27 & 58 & 91 \\
\hline & Day 2 & 269 & 61.51 & 11.95 & 24 & 61 & 104 \\
\hline & Day 3 & 206 & 64.53 & 13.09 & 34 & 64.5 & 105 \\
\hline \multirow{4}{*}{ Diastolic pressure } & Day 0 & 340 & 33.24 & 9.31 & 12 & 32 & 98 \\
\hline & Day 1 & 387 & 33.45 & 8.43 & 8 & 33 & 65 \\
\hline & Day 2 & 270 & 36.49 & 9.94 & 10 & 35.5 & 72 \\
\hline & Day 3 & 206 & 38.46 & 11.46 & 12 & 37.5 & 76 \\
\hline
\end{tabular}

*Number corresponding to the sum of records found in the medical records of each NB included in the study, over the period analyzed.
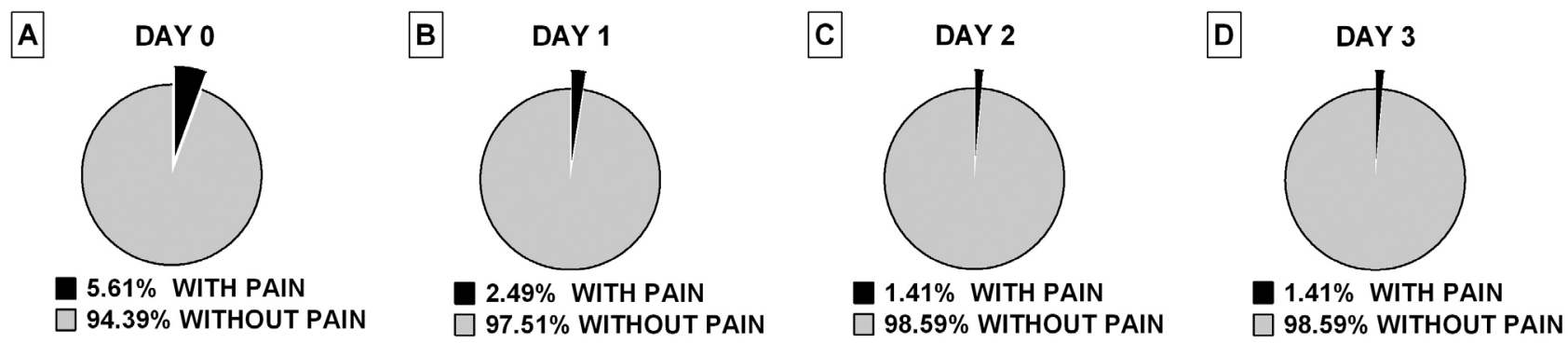

Figure 3 - (A-D) Percentage of NB with records corresponding to the presence or absence of pain (NIPS > 3), from admission (D0) to the third day (D3) of admission to the NICU. São Paulo, 2020.

weight, non-pharmacological and pharmacological strategies, NIPS, heart rate, respiratory rate, saturation, blood pressure $)$ were evaluated. A positive correlation $(r=0.339$; $\mathrm{p}<0.001$ ) was found only between the number of procedures and the use of pharmacological measures.

\section{DISCUSSION}

The NBs included in this study underwent 2,732 painful and stressful procedures, with a mean of 30.36 procedures per NB between D0 and D3, which corresponds, on average, to 7.6 procedures per NB per day. Most procedures were performed on admission (D0), with a mean of 12.78 procedures per NB, mainly due to the need to stabilize the NB in the first hours of life. The data found are in line with those presented in similar studies conducted in the country. In a previous study conducted at the same institution between 2013 and 2014, a mean of 6.6 invasive procedures per day was observed in NBs who remained, on average, nine days in the hospital ${ }^{(10)}$. In another study conducted in an inland city of the state of São Paulo, the daily mean was 5.4 procedures performed in the first week of hospitalization in preterm $\mathrm{NB}^{(11)}$. Finally, in a study carried out in a NICU in Belo Horizonte (Minas Gerais), a mean of 11.25 procedures per day per NB was observed throughout the entire hospital stay (on average, 21 days) ${ }^{(7)}$. Despite the variation in the number of procedures described, mainly resulting from the different methodological designs of the studies presented, NBs are repeatedly exposed to painful and stressful procedures during hospitalization. 
The painful procedures which NBs commonly undergo in the NICU vary widely in nature and, therefore, the severity of pain caused by such interventions is also diversified ${ }^{(12)}$. Recently, procedural pain severity in neonates was classified according to NB reactivity as mild, mild to moderate, moderate, severe, and extremely severe ${ }^{(12)}$. In the present study, the most frequently performed procedures were hell prick for capillary blood glucose (21\%) and UAW and/or orotracheal cannula (OTC) suctioning (14\%), procedures classified as causing mild to moderate pain. The results of the present study are similar to those observed in other studies, in which the invasive procedures frequently performed in the NICU were heel puncture and nasal/oral suctioning $^{(3,13)}$.

Despite the high number of painful procedures, in 21.1\% of the medical records, no non-pharmacological measures were documented between admission (D0) and the third day of hospitalization (D3). The non-pharmacological strategies most frequently used in this study were dim lighting (28\%) and coziness in bed/nesting (26\%), interventions that are not analgesic, but that contribute to pain relief and neonatal comfort, especially when combined to other interventions. Similar results were found in another study, in which the most frequently used non-pharmacological measures included coziness in the bed/nesting (26\%) and environment control by dim lighting $(20 \%)^{(7)}$.

Evidence suggests that the decrease in multisensory stimulation, which includes the reduction of light and noise, can decrease the response to pain associated with painful and stressful procedures ${ }^{(14)}$. It is pointed out that the results of different literature reviews reinforce the effectiveness of non-pharmacological strategies in reducing neonatal pain. Breastfeeding, skin-to-skin contact, sucrose and glucose are the most frequently studied strategies and those with the highest level of evidence regarding effectiveness and safety ${ }^{(15,16)}$. Despite the evidence on non-pharmacological measures for pain relief in newborns, it is questionable how these strategies are implemented in clinical practice, as numerous factors can limit their adoption, such as, for example, the lack of knowledge about the effectiveness and benefits of these methods ${ }^{(17)}$. It is also highlighted that behavioral and environmental interventions are rarely documented ${ }^{(3)}$.

With regard to pharmacological strategies, no records of analgesic and sedative drug administration were found in approximately $80 \%$ of the analyzed records, despite the high number of painful and stressful procedures recorded. Similar results were previously described ${ }^{(7,18)}$. In the present study, it is highlighted that the main pharmacological measure used was continuous fentanyl (49\%). Another study showed that the main pharmacological measure used was intermittent fentanyl $(72 \%)^{(7)}$. In another study, for example, the most frequent pharmacological intervention was the combination of midazolam and fentanyl $(37.8 \%)^{(10)}$.

It is important to emphasize that, despite being registered by the nursing team, the continuous infusion of opioids (such as morphine and fentanyl) is not very effective in relieving pain resulting from procedures in $\mathrm{NBs}^{(19)}$. It should also be noted that the use of benzodiazepine sedatives such as midazolam, despite being common in the national scenario, is not indicated for the control of neonatal pain ${ }^{(19)}$.

In general, the lack of institutional protocols for procedural pain relief in neonates admitted to the NICU contributes to the insufficient number of occasions on which NBs received pharmacological or non-pharmacological analgesia. Repeated and untreated painful experiences during hospitalization in the NICU occur during a critical period of neurodevelopment and are associated with the future development of sensorineural, cognitive, psychobehavioral, and pain processing disorders ${ }^{(20)}$. Therefore, expanded efforts are required to assess and reduce the number of painful procedures, as well as to improve pain management, since, unlike the neonates' clinical factors, organizational factors can be modified to promote adequate pain management ${ }^{(21)}$.

There was a reduction in the NIPS score values recorded from admission to the third day. Pain recordings are performed, for the most part, together with the assessment of vital signs, according to the institutional protocol. However, procedural pain assessment is not adequately performed. Thus, the inconsistency between pain records and the actual painful experience of the newborns included in this study is highlighted. Similar results were observed in a study carried out at the NICU at the same institution, in which it was found that the application of the NIPS scale does not reflect the condition experienced by the $\mathrm{NB}$, considering the number of procedures performed ${ }^{(10)}$. It should be noted that the behavioral assessment relies on the interpretation of the professional who is at the bedside, who in turn is influenced by several aspects, such as the NB's clinical condition, professional knowledge and skills, organizational conditions, among other factors.

Despite the existence of a variety of validated instruments, they are rarely used in clinical practice ${ }^{(22)}$. Data presented in this study, as well as results described in other studies developed in national and international settings, confirm that neonatal pain is not sufficiently assessed ${ }^{(7)}$. Additionally, it is evident that pain management remains suboptimal in neonatal units, suggesting a gap between research evidence and the translation of knowledge into clinical practice ${ }^{(23)}$.

Regarding vital signs, it was found that the heart rate fluctuated within the normal range during the stay in the NICU. It is known that heart rate, used in isolation, is nonspecific for pain assessment, as values can vary due to numerous conditions, such as pathologies and medication use, for example. Respiratory rate and peripheral oxygen saturation, however, remained in the upper reference limit, which possibly reflects the main hospitalization diagnosis, respiratory affections. Some newborns remained on oxygen and ventilatory support, which may have interfered not only with respiratory rate and oxygen saturation, but also with other vital parameters. It is also worth noting that a pattern related to biometric data was not observed over the period studied, in relation to painful procedures or analgesic strategies used. 
The results of this study, as well as other research in the Brazilian scenario ${ }^{(7,10,11)}$, demonstrate a high number of painful procedures and the scarcity of analgesic interventions. In Canadian NICUs, for instance, studies show a small number of procedures causing tissue damage, 5.8 procedures, on average, per week, with analgesia used in half of these procedures $^{(24)}$ and, more recently, an average of 1.75 procedure per day, by $\mathrm{NB}$, and about $60 \%$ of the procedures were performed with some type of analgesia ${ }^{(2)}$. It can be said that the main barrier in Brazil is not the production of knowledge, but its translation aimed at applying knowledge in clinical practice, focusing on overcoming barriers ${ }^{(5)}$, which include, for example, the lack of access to reliable information in accessible language, lack of protocols and institutional guides, difficulty in incorporating new practices. Properly implementing knowledge can ensure that neonates and their families have access to evidence-based pain assessment, as well as safe and effective pain relief ${ }^{(5)}$.

For example, the interprofessional intervention NEODOLC) (NEOnato DOLore) aimed to improve procedural pain management in a Swiss NICU. A systematic and coordinated approach was used to educate health professionals, facilitate parental involvement in care, and apply scientific evidence to improve communication between health professionals and parents, documentation of care, and facilitate the translation of knowledge into clinical practice $^{(25)}$. Also noteworthy is the Implementation of Infant Pain Practice Change $(\mathrm{ImPaC})$ Resource, an online tool developed to foster practice change related to pain assessment and management in neonatal units ${ }^{(26)}$.

Therefore, procedural pain prevention in NBs may include not only pharmacological and non-pharmacological assessment and treatment per se, but should extend to knowledge translation and implementation strategies, involving professional health education, interprofessional collaboration, the involvement of parents and organizational issues $^{(27,28)}$. Such strategies should be turned towards the Brazilian context and the local needs, either of the institution, professionals, newborns, or their families.

As limitations of the study, it can be pointed out that vital signs, as well as pain scores, were collected from the NB's clinical records, from records at pre-established times, according to the unit's routine. These data are not directly related to the painful procedures performed, limiting their interpretation for this study. The time established for data collection (D0 to D3) proved to be of great relevance for the identification of potentially painful procedures, although it may have limited the understanding of the newborn's painful experience in the NICU over an extended interval.

Finally, it is observed that the literature presents a significant body of evidence of changes in neurodevelopment, behavioral disorders and pain processing resulting from deleterious events associated with repeated and untreated pain in neonates ${ }^{(13,20,21)}$, as well as from benefits and safety of several non-pharmacological strategies, such as breastfeeding, skin-to-skin contact, and sucrose, for example, for pain relief ${ }^{(15,16,21)}$. This reinforces the need to develop simple and effective measures for pain assessment and management, as well as the implementation of clinical protocols, to contribute to a comprehensive and differentiated understanding of pain, improving nursing care for newborns.

\section{CONCLUSION}

Hospitalized newborns are exposed to a high number of painful and stressful procedures, and the use of pain relief measures is insufficient. The physiological and behavioral parameters systematically recorded throughout hospitalization do not necessarily reflect the number of interventions the NBs undergo. Future research should focus on developing and evaluating knowledge translation strategies to improve neonatal pain management.

\section{RESUMO}

Objetivo: Caracterizar os procedimentos dolorosos, estratégias analgésicas, sinais vitais e os escores de dor em recém-nascidos hospitalizados. Método: Estudo clínico primário, observacional, prospectivo, desenvolvido em um hospital público brasileiro. Dados demográficos, procedimentos dolorosos, medidas de alívio da dor, sinais vitais e escores de dor foram coletados dos prontuários clínicos de 90 recém-nascidos admitidos na unidade de terapia intensiva e avaliados entre a admissão e o terceiro dia de internação. Para a análise estatística foram utilizados o programa Statistic Package for the Social Sciences e o Software R. Resultados: Os recém-nascidos foram submetidos a 2.732 procedimentos dolorosos, 540 estratégias não farmacológicas e 216 farmacológicas. O procedimento mais realizado foi a lancetagem de calcâneo (20,96\%). A estratégia não farmacológica mais comumente registrada foi a redução de luminosidade $(28,33 \%)$ e o fentanil contínuo $(48,83 \%)$ foi a principal medida farmacológica adotada. O escore de dor e os sinais vitais apresentam variabilidade no período avaliado. Conclusão: A despeito do número elevado de procedimentos dolorosos, os registros de avaliação da dor não refletem a dor procedural e o uso das estratégias analgésicas foi insuficiente.

\section{DESCRITORES \\ Dor; Recém-Nascido; Cuidados Críticos.}

\section{RESUMEN}

Objetivo: Caracterizar los procedimientos dolorosos, estrategias analgésicas, señales vitales y los scores de dolor en recién nascidos hospitalizados. Método: Estudio clínico primario, de observación, prospectivo, desarrollado en un hospital público brasileño. Datos demográficos, procedimientos dolorosos, medidas de alivio del dolor, señales vitales y scores de dolor fueron seleccionados de las historias clínicas de 90 recién nacidos admitidos en la unidad de cuidados intensivos y evaluados entre la admisión y el tercer día de hospitalización. Para el análisis estadístico fueron utilizados el programa Statistic Package for the Social Sciences y el Software R. Resultados: Los recién nacidos fueron sometidos a 2.732 procedimientos dolorosos, 540 estrategias no farmacológicas y 216 farmacológicas. El procedimiento más realizado fue la punción del talón (20,96\%). La estrategia no farmacológica más común fue 
la reducción de luminosidad (28,33\%) y el fetanyl continuo (48,83\%) fue la principal medida farmacológica adoptada. Conclusión: A pesar del número elevado de procedimientos dolorosos, los registros de evaluación del dolor no reflejan el dolor procedural y el uso de las estrategias analgésicas fue insuficiente.

\section{DESCRIPTORES}

Dolor; Recién Nacido; Cuidados Críticos.

\section{REFERENCES}

1. Jordão KR, Pinto LA, Machado LR, Costa LB, Trajano ET. Possible stressors in a neonatal intensive care unit at a university hospital. Rev Bras Ter Intensiva. 2016;28(3):310-4. DOI: https://doi.org/10.5935/0103-507X.20160041.

2. Orovec A, Disher T, Caddell K, Campbell-Yeo M. Assessment and management of procedural pain during the entire neonatal intensive care unit hospitalization. Pain Manag Nurs. 2019;20(5):503-11. DOI: https://doi.org/10.1016/j.pmn.2018.11.061.

3. Cruz MD, Fernandes AM, Oliveira CR. Epidemiology of painful procedures performed in neonates: a systematic review of observational studies. Eur J Pain. 2016;20(4):489-98. DOI: https://doi.org/10.1002/ejp.757.

4. Raja SN, Carr DB, Cohen M, Finnerup NB, Flor H, Gibson S, et al. The revised International Association for the Study of Pain definition of pain: concepts, challenges, and compromises. Pain. 2020;161(9):1976-82. DOI: https://doi.org/10.1097/j.pain.0000000000001939.

5. Eccleston C, Fisher E, Howard RF, Slater R, Forgeron P, Palermo TM, et al. Delivering transformative action in paediatric pain: a Lancet Child \& Adolescent Health Commission. Lancet Child Adolesc Health. 2021;5(1):47-87. DOI: https://doi.org/10.1016/S2352-4642(20)30277-7.

6. Christoffel MM, Castral TC, Daré MF, Montanholi LL, Gomes ALM, Scochi CGS. Attitudes of healthcare professionals regarding the assessment and treatment of neonatal pain. Esc. Anna Nery. 2017 [cited 2021 Oct 6];21(1):e20170018. Available from: https://www. scielo.br/j/ean/a/JFQ4N4gDZNN44q3kFD8dfjv/?lang=en.

7. Maciel HIA, Costa MF, Costa ACL, Marcatto JO, Manzo BF, Bueno M. Pharmacological and nonpharmacological measures of pain management and treatment among neonates. Rev Bras Ter Intensiva. 2019 [cited 2021 Oct 6];31(1):21-6. Available from: https://www. scielo.br/j/rbti/a/WDnJF38dgpWWwwmwrDFStdP/?lang=en.

8. Costa T, Rossato LM, Bueno M, Secco IL, Sposito NP, Harrison D, et al. Nurses' knowledge and practices regarding pain management in newborns. Rev Esc Enferm USP. 2017;51:e03210. DOI: https://doi.org/10.1590/S1980-220X2016034403210.

9. Motta GC, Schardosim JM, Cunha ML. Neonatal Infant Pain Scale: cross-cultural adaptation and validation in Brazil. J Pain Symptom Manage. 2015;50(3):394-401. DOI: https://doi.org/10.1016/j.jpainsymman.2015.03.019.

10. Sposito NPB, Rossato LM, Bueno M, Kimura AF, Costa T, Guedes DMB. Assessment and management of pain in newborns hospitalized in a Neonatal Intensive Care Unit: a cross-sectional study. Rev Lat Am Enfermagem. 2017;25:e2931. DOI: https://doi.org/10.1590/15188345.1665.2931.

11. Bonutti DP, Daré MF, Castral TC, Leite AM, Vici-Maia JA, Scochi CGS. Dimensioning of painful procedures and interventions for acute pain relief in premature infants. Rev Lat Am Enfermagem. 2017;25:e2917. DOI: https://doi.org/10.1590/1518-8345.1387.2917.

12. Laudiano-Dray MP, Pillai Riddell R, Jones L, Iyer R, Whitehead K, Fitzgerald $M$, et al. Quantification of neonatal procedural pain severity: a platform for estimating total pain burden in individual infants. Pain. 2020;161(6):1270-7. DOI: https://doi.org/10.1097/ j.pain.0000000000001814.

13. Cong X, Wu J, Vittner D, Xu W, Hussain N, Galvin S, et al. The impact of cumulative pain/stress on neurobehavioral development of preterm infants in the NICU. Early Hum Dev. 2017; 108:9-16. DOI: https://doi.org/10.1016/j.earlhumdev.2017.03.003.

14. Hatfield LA, Murphy N, Karp K, Polomano RC. A Systematic review of behavioral and environmental interventions for procedural pain management in preterm infants. J Pediatr Nurs. 2019;44:22-30. DOI: https://doi.org/10.1016/j.pedn.2018.10.004.

15. Mangat AK, Oei JL, Chen K, Quah-Smith I, Schmölzer GM. A review of non-pharmacological treatments for pain management in newborn infants. Children (Basel). 2018;5(10):130. DOI: https://doi.org/10.3390/children5100130.

16. Gomes Neto M, da Silva Lopes IA, Araujo ACCLM, Oliveira LS, Saquetto MB. The effect of facilitated tucking position during painful procedure in pain management of preterm infants in neonatal intensive care unit: a systematic review and meta-analysis. Eur J Pediatr. 2020;179(5):699-709. DOI: https://doi.org/10.1007/s00431-020-03640-5.

17. Pölkki T, Korhonen A, Laukkala H. Nurses' perceptions of pain assessment and management practices in neonates: a cross-sectional survey. Scand J Caring Sci. 2018;32(2):725-33. DOl: https://doi.org/10.1111/scs.12503.

18. Kaur H, Negi V, Sharma M, Mahajan G. Study of pain response in neonates during venipuncture with a view to analyse utility of topical anaesthetic agent for alleviating pain. Med J Armed Forces India. 2019;75(2):140-5. DOI: https://doi.org/10.1016/j.mjafi.2017.12.009.

19. Committee on Fetus and Newborn and Section on Anesthesiology and Pain Medicine. Prevention and management of procedural pain in the neonate: an update. Pediatrics. 2016;137(2):e20154271. DOl: https://doi.org/10.1542/peds.2015-4271.

20. Williams MD, Lascelles BDX. Early neonatal pain - a review of clinical and experimental implications on painful conditions later in life. Front Pediatr. 2020;8:30. DOI: https://doi.org/10.3389/fped.2020.00030.

21. Coviello C, Popple Martinez M, Drovandi L, Corsini I, Leonardi V, Lunardi C, et al. Painful procedures can affect post-natal growth and neurodevelopment in preterm infants. ActaPaediatr. 2018;107(5):784-90. DOI: https://doi.org/10.1111/apa.14222.

22. Eriksson M, Campbell-Yeo M. Assessment of pain in newborn infants. Semin Fetal Neonatal Med. 2019;24(4):101003. DOI: https://doi. org/10.1016/j.siny.2019.04.003.

23. Ho LP, Ho SS, Leung DY, So WK, Chan CW. A feasibility and efficacy randomised controlled trial of swaddling for controlling procedural pain in preterm infants. J Clin Nurs. 2016;25(3-4):472-82. DOI: https://doi.org/10.1111/jocn.13075.

24. Johnston C, Barrington KJ, Taddio A, Carbajal R, Filion F. Pain in Canadian NICUs: have we improved over the past 12 years? Clin J Pain. 2011;27(3):225-32. DOI: https://doi.org/10.1097/AJP.0b013e3181fe14cf. 
25. Balice-Bourgois C, Zumstein-Shaha M, Simonetti GD, Newman CJ. Interprofessional collaboration and involvement of parents in the management of painful procedures in newborns. Front Pediatr. 2020;8:394. DOI: https://doi.org/10.3389/fped.2020.00394.

26. Bueno M, Stevens B, Barwick MA, Riahi S, Li SA, Lanese A, et al. A cluster randomized clinical trial to evaluate the effectiveness of the Implementation of Infant Pain Practice Change (ImPaC) Resource to improve pain practices in hospitalized infants: a study protocol. Trials. 2020;21(1):16. DOI: https://doi.org/10.1186/s13063-019-3782-9.

27. Balice-Bourgois C, Zumstein-Shaha M, Vanoni F, Jaques C, Newman CJ, Simonetti GD. A systematic review of clinical practice guidelines for acute procedural pain on neonates. Clin J Pain. 2020;36(5):390-8. DOI: https://doi.org/10.1097/AJP.0000000000000808.

28. Vieira ACG, Gastaldo D, Harrison D. How to translate scientific knowledge into practice? Concepts, models and application. Rev Bras Enferm. 2020;73(5):e20190179. DOI: https://doi.org/10.1590/0034-7167-2019-0179.

Conselho Nacional de Desenvolvimento Científico e Tecnológico (CNPq). Process 308797/2017-5. 